\title{
PSICO-EDUCAÇÃO: A CIÊNCIA DO "VIVER COM" EDUCATIVO E TERAPÊUTICO
}

André Lebon'

\section{RESUMO}

$O$ presente trabalho apresenta, em linhas gerais, o modelo de intervenção sócio-educativo desenvolvido e implementado no Canadá, denominado Psico-Educação. Neste sentido, faz-se um breve histórico remetendo-se aos primórdios da Educação Especializada junto a crianças $e$ adolescentes em situação de risco psicossocial até chegar à Psico-educação, colocando-a como elaboração de ponta na busca de sistematização da prática educativa realizada no cotidiano das instituições. Na sequência apresentam-se os conceitos teórico-práticos subjacentes a essa abordagem, ressaltando também os princípios ligados à formação profissional na área.

\section{Desde quando a educação especializada existe?}

Em pesquisa bibliográfica feita, Maurice Capul, co-autor com o Dr. Michel Lemay do volume "De L'education specialisée", publicado em maio de 1996, encontrou citações que datam do século XII, evidenciando as bases e atitudes educativas e, até mesmo, formas de proteção em relação às crianças carentes. Citaremos alguns exemplos:

"Vocês terão nos hospitais um local especial destinado a receber as crianças expostas... Vocês terão o cuidado de dar-lhes os mestres os mais eruditos escolhidos entre vocês, que sejam amáveis e que os amem. É melhor repreender que bater nas crianças".

Instruções aos religiosos da Ordem do Espírito Santo, fundada em 1160 por Guy, Conde de Montpellier, evidenciando uma preocupação fora do comum para a época

"Uma educação adequada de fato, terá repercussões a longo prazo na assitência em geral: estas crianças estão sendo educadas atualmente na perversão sendo que a instrução infantil tem uma grande influência para o resto da vida".

1 Mestre em Psico-educação pela Universidade de Montreal e coordenador do Centro de Psico-educação do Québec.

Paidéia FFCLRP-USP, Rib.Preto, fev/ago 97. 
Trecho de documento intitulado: "De L'assistance aux pauvres" publicado em Bruges em 1526.

"Existe todo interesse em educar as crianças em escolas públicas abertas a todos meninos e meninas".do mesmo autor.

"Eu vivi durante anos junto com mais de cinquenta jovens mendigos; na pobreza, dividi com eles meu pão; vivi, eu mesmo, como um mendigo para ensinar-lhes a viver como homens". Henri Pestalozzi, 1746

"Um método médico-pedagógico é um método que leva em conta as anomalias psicológicas e fisiológicas, um método que, para cada criança, parte do conhecido e do possivel, do mais baixo possível na escala das funções, para levar gradualmente e sem lacuna ao conhecido $e$ ao possível de todo mundo". Edouard Séguin, anos 1850

Este rápido panorama nos permite entrever, desde épocas mais remotas, premissas de uma real filosofia da educação e os ingredientes de base do atual modelo da psico-educação: 1 - Interesse pelas as crianças; 2- Reconhecimento de que aquilo que é aprendido quando criança é portador de sentido para toda a vida; 3-Noção de desafio pedagógico, que diz que é preciso ir ao encontro da criança onde ela está; 4-Noção de normalização e integração, quando se fala de "esperança de recuperar os mais carentes, de integrar os meninos e meninas", as escolas públicas, etc.

Conclui-se que a educação especializada não é uma preocupação totalmente nova. A evolução dos conhecimentos e as tomadas de consciência que as experiências de Bettelheim ${ }^{2}$, de $\mathrm{Neil}^{3}$, de Redi ${ }^{4}$, etc suscitaram em Jeannine Guindon e Gilles Gendreau no início dos anos 50 levaram-os a utilizar estes conhecimentos em uma visão nova que tornou-se a Psico-educação. Nesta perspectiva o educador é terapêuta no e pelo acontecimento cotidiano.

Vejamos como Guindon e Gendreau definem este modelo psicoeducativo. Citaremos, primeiramente Guindon.

"O educador é um profissional qualificado que se interessa essencialmente por todos os aspectos da vida da criança. Ele cumpre seu papel profissional compartilhando os acontecimentos quotidianos da vida da criança e planificando os momentos de vida de modo a colocar diretamente em jogo o desenvolvimento psíquico, moral social e intelectual da criança".

2- Em Um lugar onde renascer, $O$ amor não é suficiente, A escola ortogênica de Chicago.

3- Em Crianças livres de Summerhill, A liberdade pela anarquia.

4- Em A criança agressiva, As outras 23 horas. 
Esta presença "qualitativa" regular junto à criança permite ao educador fazer com que a criança descubra suas possibilidades através de um programa estruturado, favorecendo sua participação em atividades de grupo e em uma vida de grupo. Pode-se então dizer que o educador contribui para o processo de socialização do jovem.

Através dos contatos cotidianos, o educador desenvolve com a criança uma relação profunda, sobretudo no plano de suas inquietações e de seus sentimentos. A influência terapêutica do educador no desenvolvimento da criança é completada na e pela intervenção prática tornada possível pela sua presença, bastante contínua, na vida cotidiana da criança.

Gendreau:

A esta definição geral, acrescentamos algumas reflexões de

"A intervenção psico-educativa inscreve-se na perspectiva do meio total e não existe insignificâncias em educação. nenhuma presença é mais nobre que outra quando nos tornamos educadores no e pelo acontecimento"

O que faz com que a psico-educação seja revolucionária é justamente que ela fêz uma Ciências e uma arte da relação e da ação educativa no compartilhar do cotidiano, que com frequência consideramos banal e insignificante. Revolucionária ela também é ao lembrar a todos que o sujeito (o jovem) está no coração de toda intervenção, que todos seus gestos, suas palavras, seus silêncios constituem uma linguagem e que escutar esta linguagem e permitirlhe a existência é favorecer a criação de uma identidade, a emergência de uma autonomia. Permitir esta linguagem é compartilhar a vida cotidiana do sujeito e criar ao longo do dia as condições de atualização daquilo que é melhor nele.

Um outro aspecto revolucionário é que a formação de psico-educadores está integrada no ensino universitário em um departamento autônomo, onde se reconhece a psico-educação como disciplina. A formação é do mesmo nível que a dos outros profissionais das ciências humanas (psicólogos, assistentes sociais)

Uma escola universitária profissional deve se preocupar com o desenvolvimento do saber, mas também com o saber-fazer e o saber-ser. É por esta razão que em psico-educação tem-se um grande espaço para a formação prática, estágio no local de trabalho e supervisão profissional, incluindo um olhar sobre as atitudes do profissional.

\section{Os instrumentos ou ferramentas da Psico-educação}

Essencialmente, as principais características que apresentamos 
são extraídas do volume de Maurice Capul e Michel Lemay ${ }^{5}$.

\section{$\underline{\text { O vivido compartilhado }}$}

Inúmeras profissões têm como objetivo ajudar as pessoas. O que caracteriza a psico-educação é o acompanhamento no vivido compartilhado, em situações reais do aqui e agora. Seu campo de ação é o banal, o comum, o habitual, tanto quanto o surpreendente, os diversos fatos e acontecimentos cotidianos.

A ação educativa é o compartilhar de um vivido cotidiano por intermédio de trocas verbais e atividades, assim como, o engajamento do profissional em um "aqui e agora" com um ou mais sujeitos. O psico-educador é um terapeuta no e pelo acontecimento cotidiano.

\section{A relação educativa}

Poucas pessoas colocam em dúvida a idéia que a intervenção do educador baseia-se essencialmente no estabelecimento de uma relação com as pessoas que vêm até ele e que lhe são confiadas.

Esta relação significativa desenvolve-se através das diferentes funções do educador.

\section{a) A função de acompanhamento}

No respeito e na escuta do outro e sabendo que ele deve, às vezes, colocar limites, o educador quer ser suficientemente presente e útil para se tornar significativo, e ao mesmo tempo, suficientemente afastado para não impor sua direção.

Acompanhar é, frequentemente, ser uma espécie de mediador entre o sujeito (indivíduo) e seu meio. Este acompanhamento e esta mediação apelam à identificação de objetivos realistas.

\section{b) A função de avaliação}

Esta função ultrapassa em muito o aspecto relacional, pois ela está vinculada com a capacidade de compreender a dinâmica de um indivíduo ou de um grupo no conjunto de sua realidade e de suas interações. É o olhar sobre o outro para apreciar suas aptidões e seus limites a fim de propor-lhe realizações que permitam que ele se desenvolva.

5- Capul, Maurice: Lemay, Michel (1996). Educação especializada. Érès. 


\section{c) A função auxiliar do Ego}

Esta função está essencialmente centrada na adaptação à realidade, ela consiste em ajudar o sujeito a efetuar compromissos entre seu universo pulsional, as exigências sociais interiorizadas e a realidade exterior.

d) A função de testemunho da realidade e de pólo de identidade

Citaremos textualmente o Dr. Lemay:

"Nada pode nascer de humano sem o encontro com pessoas que não somente as acompanha numa atmosfera de respeito e de amor, mas revelam-se capazes de 'dizer' o que elas são, não através de um discurso verbal, mas pelo fato de ousar testemunhar o que elas são nos atos aparentemente insignificantes do cotidiano".

Esta troca relacional supõe uma duração, uma autenticidade e um engajamento. Duração ou continuidade: A sucessão de rupturas de laços que os sujeitos tiveram exige a possibilidade de encontros duráveis com pessoas significativas.

Autenticidade: Esta significação baseia-se em uma autenticidade de presença. Não se pode transformar uma visão persecutória, indiferente da existência pelo simples fato de estar próximo, fisicamente de um educador não engajado.

Engajamento: E no compartilhar, no fazer-com que se baseia o essencial da profissão de educador.

\section{e) A função de substituto parental}

A partir do momento em que a criança é tomada sob responsabilidade no desenrolar de sua vida cotidiana, desde o acordar até, e inclusive o deitar, estabelece-se inevitavelmente um modo de relação mais ou menos durável com os homens e as mulheres, que pelos seus atos e pelas suas trocas afetivas, evocam as funções habitualmente imputadas aos pais. Existe uma substituição que evoca troca, substituição, compensação e que acarreta sentimentos muito complexos na criança.

\section{f) A funcão projetiva}

Em virtude de sua função, o educador desperta no sujeito que vive momentaneamente com ele, sentimentos complexos dos quais uma parte é estranha à situação atual.

Na sua presença contínua com o passar dos dias, o educador lembra toda uma sucessão de acontecimentos oriundos da família, da escola de 
seus meios de vida (recreação, trabalho, etc) sem ser o verdadeiro portador. $O$ sujeito projeta no educador os afetos não resolvidos, modelos de funcionamento, comportamentos vindos do passado.

Desatar estas projeções no interior mesmo da ação cotidiana, no centro da ação, necessita um saber, um saber-fazer (das ações) e um saber-ser (das atitudes) que permitem ao educador acompanhar o sujeito em uma nova maneira de ser.

g) A função de modificação de comportamento

O trabalho do educador favorece o aprendizado de algumas novas condutas. Modificar as interações entre o sujeito e seu meio e modificar o modo de adaptação do sujeito fazem parte do trabalho de educador.

\section{h) A função de organizador}

Frequientemente na literatura os especialistas das ciências do homem inclinam-se para a ação terapêutica insistindo sofre uma única faceta, a de oferecer ao sujeito "uma experiência emocional corretora". Ora, o educador completa esta faceta pela sua crença na importância de um meio que o cerca com mensagens coerentes e que funcionam de maneira harmoniosa. "Um meio onde renasce", como chamaria Bruno Bettelheim, apoia-se na organização do meio em função das necessidades dos jovens ou adultos que nele se encontram. É o que abordaremos mais adiante quando falarmos das atividades que ilustrarão o potencial de um meio de vida transformador que visa criar as melhores condições possíveis.

\section{i) A função de mediador}

Ser mediador é colocar-se no meio. Ora, o educador é sempre este personagem que tenta estabelecer uma ponte entre um ser e seu meio (familiar, social, relacional, funcional, etc) A mediação é a intervenção na qual a presença de um terceiro (o educador) permite a casais, a crianças, a famílias, retornar às mensagens passadas confusas, deformadas ou retidas. A arte do mediador consiste em oferecer um espaço e a garanti-lo pela sua presença, levando assim as pessoas envolvidas a nomear estas confusões e a resituá-las de maneira mutuamente satisfatória.

\section{j) A funcão de revelador de mal-estar individual e social}

Esta função decorre do dilema em que está mergulhado todo 
educador, dividido entre dois extremos, dois pólos.

O primeiro pólo é sua intervenção na prática, o acompanhamento de um indivíduo nas suas dificuldades pessoais, relacionais e que visa aumentar a adaptação do sujeito às exigências de uma sociedade, valorizando as condutas conformes às expectativas e socialmente aceitáveis

O segundo pólo é a tomada de consciência do peso pavoroso das pobrezas socio-econômicas sobre a gênese das dificuldades dos indivíduos. $\mathrm{O}$ educador é interpelado a revelar, a denunciar as situações sociais geradoras de injustiças, de carência ou de revolta. O educador está presente para querer modificar estas situações de injustiça ou estas condições de vida. Torna-se, às vezes, escandaloso em querer readaptar um sujeito em um meio e nas condições de vida que o destroem. Esta situação acarreta, às vezes, a vontade de agir socialmente e de levantar bandeiras de mudanças de ordem sócio-políticas.

\section{A animação de grupos educativos}

Se o educador deve estabelecer uma relação individualizada com cada um, sua ação desenvolve-se freqüentemente no interior do grupo. Que seja o fruto de um agrupamento espontâneo de um bairro ou em uma escola, ou que esteja ligado a uma associação mais estruturada, o grupo reveste-se de um potencial educativo que o educador tentará utilizar ao máximo. Resumiremos previamente os potenciais educativos.

\section{a) $Q$ grupo é um lugar de socialização}

A vida coletiva com suas inevitáveis frustrações e também com suas alegrias permite aos membros de um grupo exercitarem-se com as tarefas que toda vida em comum impõe: é preciso ensiná-los a negociar suas próprias questões em função das dos outros, a admitir certas diferenças. $\mathrm{O}$ grupo torna-se progressivamente um lugar de trocas onde cada um aprende a situarse em relação ao outro, encontrando um território e símbolos coletivos que permitem falar com orgulho de "NOS, o grupo".

O conjunto das realizações do grupo permite traçar uma rede singular de interações sempre favorecendo a descoberta da força afetiva das coproduções.

b) Q grupo permite conhecer-se no seu próprio funcionamento em relação ao outro 
O valor de um acompanhamento educativo está em poder levar os sujeitos que vivem juntos a conhecerem ao mesmo tempo, o que eles são aos olhos dos outros e o que os outros são para eles.

Pode-se falar de um verdadeiro espelho, mas também de um laboratório social no qual pelos seus atritos, as desuniões e as reconciliações cotidianas, cada um revive os problemas de comunicação vividos anteriormente e pode-se modificar algumas respostas graças às interpretações e à utilização feitas pelo educador.

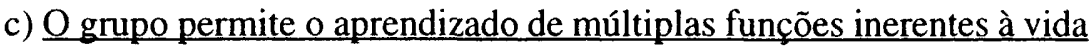
coletiva

Tomada de responsabilidade, aceitação dos papéis, negociações por ocasião de divergências, estabelecimento de canais de comunicação, etc.

$O$ saber-fazer educativo consiste em estar atento às potencialidades que a vida coletiva oferece e a utilizá-las para permitir aprendizagens corretivas

\section{d) $\underline{O}$ grupo é um lugar de realização}

O grupo evolui graças à sua capacidade de realizar um conjunto de atividades que une os membros. $O$ saber-fazer da educação baseia-se na sua capacidade de mobilizar o grupo na realização de atividades construtivas.

\section{e) O grupo é um lugar de expressão}

A vida coletiva pode criar condições de escuta e empatia mútuas que favorecem os desejos de expressão de cada um.

Quando se sabe quantos jovens sofrem de solidão, de desvalorização, quando se sabe quantos são incapazes de dar um sentido à própria vida, compreende-se que a integração em um grupo pode constituir um fato determinante em suas existências.

\section{f) Q grupo é um lugar de encontro}

Além da possibilidade de se expressar, o grupo torna-se um lugar de encontro significativo, pois ele permite a fuga da solidão, a descoberta de colegas, o conhecimento de certo nível de convivência por intermédio de refeições, jogos e atividades realizadas em comum. 


\section{g) O grupo é portador de normas}

Um grupo deixado a ele mesmo pode ser um lugar de contágio coletivo, substituindo-se ao EU de modo a não responsabilizar os membros a GENTE convida-os a se afogarem em um magma em fusão onde tudo torna-se permitido. O grupo pode também tornar-se um meio de regulamentar as condutas sociais construindo assim, um sistema de regras, de opiniões e de atitudes que se tornam a lei do grupo.

Algumas constatações falam em favor da utilização do grupo como meio de apoiar o indivíduo que quer mudar através da integração de novas orientações de vida:

- Os grupos mobilizam forças que produzem efeitos importantes nos indivíduos;

- As normas estabelecidas em comum no grupo tendem a se tornar normas pessoais;

-É, freqüentemente, mais fácil mudar os comportamentos de um indivíduo em grupo que quando ele está sozinho;

- As trocas individuais no grupo têm mais chance de serem duráveis.

\section{A animação das atividades}

Basta observar uma criança no seu meio familiar, escolar ou de lazer para descobrir que ela $\hat{e}$, principalmente, um ser entrando em relação com as pessoas e os objetos por intermédio de atos essencialmente criativos.

Vejamos o que diz o Dr. Lemay:

"É pela ação ( atividade) que a criança ressente e se representa seu corpo, é por ela que a criança ocupa um lugar e inscreve-se em uma série de sequências temporais, cuja continuidade e o esforço empregado para mantê-los vão tecer uma trama chamada passado, é pela ação que ela descobre a alegria do domínio de um meio, mas também os limites impostos por este meio. É na troca de uma ação que ele faz o encontro de sujeitos amados, que ele retirará parcelas de identificação construindo suas próprias imagens. É nesta ação que ele nomeará, escreverá, representará seu mundo inteiro pelo jogo, o grafismo ou qualquer outra forma de expressão simbólica. É no centro de uma ação que ele entrará em comunicação com seus pares, descobrirá a alegria da convivência, mas também as frustrações inerentes a toda vida em comum". 
A psico-educação utiliza ao máximo o meio de vida como universo terapêutico. A maneira pela qual se organizam e animam-se as atividades da vida cotidiana pode acelerar ou fazer com que entre em curto-círcuito o processo terapêutico e, consequentemente, a mudança.

O princípio sobre o qual se apoia esta abordagem é o seguinte: a instalação de um meio, de um programa e de atividades que ofereçam ao sujeito um universo, simulações, motivações e uma possibilidade de realizações que respondam as suas necessidades, deveriam fazer-lhe tomar consciência de seu potencial (forças e fraqueza) e de seu funcionamento, e ajudá-lo a adquirir as habilidades sociais necessárias para se desenvolver e encontrar um sentido para sua exịstência.

Com alguns tipos de crianças e jovens, a atividade torna-se um meio privilegiado de entrar em relação. As crianças carentes, por exemplo têm necessidade de uma continuidade: uma mesma atividades deve ser feita sempre no mesmo local, na mesma hora, com a mesma pessoa e utilizando os mesmos objetos. Esta "estabilidade" permite contrapor-se ao modelo de quebra de relações. Com os delinqüentes especialistas do "acting out", ou seja, "a passagem ao ato" a troca verbal é pouco útil e as psicoterapias tradicionais são geralmente pouco eficazes. É preciso, antes de tudo, encontrá-los onde eles estão, quer dizer, na rua e oferecer-lhes atividades concretas. Quanto às crianças psicóticas, elas têm necessidade que criemos para elas, cada dia, um meio estimulante podendo favorecer o nascimento do se EU.

Um programa, atividades, estas são ocasiões de emergência. Mas é preciso fazer um retorno sobre a atividade (utilização) a fim de levar o jovem a se ver em ação, a reconhecer o real e a ajudar seu comportamento. Esta terapia do imediato permite à criança questionar-se sobre ela mesma e sobre o real. Isto também faz parte do trabalho do educador.

\section{A entrevista educativa}

Durante todo o tempo em que ele acompanha um jovem, o educador propõe-lhe um conjunto de atividades que o confrontam inevitavelmente com suas capacidades e com seus limites, o que o leva a viver sucessos e fracassos.

Os encontros regulares com o educador são, para o jovem, a ocasião para falar novamente sobre os acontecimentos da semana, para nomear seu vivido, para evocá-lo, apropriar-se dele.

O acompanhamento clínico, encontro regular num momento e lugar precisos, é um momento privilegiado em que o jovem pode se permitir 
expressar dificuldades ou seus tormentos, e mesmo acusar o educador de ser a causa de todas suas infelicidades. Ele pode viver impunemente sua dor, sua cólera, sua raiva enquanto que, o educador o leva a encontrar um sentido para os diversos tipos de relação que ele estabelece com sua família, seus pares, os educadores. $\mathrm{O}$ educador aproveita destes encontros para fazer o jovem ver os padrões de seus comportamentos repetitivos e dar um sentido àquilo que ele observa no jovem em diferentes contextos.

Um encontro deste supõe que o educador faça prova das atitudes de base de toda entrevista (escuta, respeito, etc), mas é claro que ele fica muito tentado pelas situações, conflitantes ou não, que o educador viveu durante a semana com a criança ou adolescente. O que dá força e originalidade a estas trocas é precisamente que os dois protagonistas tenham assistido ao mesmo acontecimento, mas que eles não os decodifiquem sempre da mesma maneira. objetivos:

A entrevista educativa regular permite ao jovem perseguir vários

- Tomar consciência de certos comportamentos.

- Lembrar-se de seus êxitos e encarar-se de maneira mais positiva.

- Refazer a cronologia dos acontecimentos, rever seu desenrolar no espaço.

- Descobrir sua aptidão para intervir em acontecimentos e antecipá-los.

- Estabelecer uma relação entre seus comportamentos atuais e passados.

- Decodificar alguns sinais ou algumas situações que não foram compreendidas.

- Aprender a sintetizar.

- Descobrir suas aptidões em uma atividade.

- Saber expressar suas emoções e seus estados de tensão substituindo a ação pela palavra.

- Descobrir o prazer da comunicação verbal.

\section{O trabalho com as familias}

Segundo a mentalidade que prevalecia nos anos 50 e 60 , primeiros anos da psico-educação, e os conhecimentos que já se tinha na época, acreditava-se que era preciso retirar os jovens de seu meio natural. Presumia-se, de fato, que o jovem vivia em meio pouco propício a seu desenvolvimento e era melhor oferecer-lhe um meio de estilo cuidados intensivos onde tudo contribui- 
ria para sua readaptação: relações significativas com adultos de qualidade, atividades suscetíveis de aumentar sua auto-estima, interações enquadradas e estimulantes com outros jovens podendo favorecer o desenvolvimento de novas habilidades sociais. Esta concentração de fatores favoráveis permitia esperar-se que, uma vez saindo do internato, o jovem estaria pronto para refazer, sobre novas bases, relações com sua família, seus amigos, seu meio. Entretanto, as pesquisas que Le Blanc e outros realizaram em Boscoville mostraram que, apesar de todos os sucessos observados no internato, a taxa de fracasso e reincidência era sobretudo alta, e que a reinserção social dos adolescentes delinqüentes não tinha êxito.

Estes resultados forçaram o conjunto dos educadores, e a psicoeducação em geral, a reconsiderar seu trabalho com a família, os amigos e o meio natural do jovem.

As novas abordagens (Abordagem Sistêmica, "Empowerment"), fizeram aflorar a importância do trabalho educativo junto das famílias na intervenção de readaptação. De acordo com estas abordagens, os contatos são mantidos, o jovem $E$ os pais encontram seus papéis de primeiros responsáveis por seu destino, o educador age como mediador. $O$ procedimento terapêutico, que prepara junto o jovem e sua família, ajudará cada um a descobrir suas competências e a se apropriar delas. Cada um encontrará assim, confiança suficiente e auto-estima para poder enfrentar e resolver os problemas.

Este modo de fazer implica que se centre sobretudo sobre as forças das pessoas e não nas suas fraquezas e que se dê a cada um o poder de agir em uma situação problemática. $O$ movimento em direção a um alargamento da intervenção que integra a família imediata, engloba igualmente o meio da criança, seu meio natural.

As possibilidades de alianças educativas são múltiplas. Recentes pesquisas mostraram que se pode constituir toda uma rede de ajuda no próprio meio, mesmo de um jovem em dificuldade. Este último encontra muitos adultos e pode manter com eles laços privilegiados mesmo em se tratando de professores, comerciantes, animadores de lazer, vizinhos ou outros. Compete, então, ao educador mostrar a estas pessoas o papel que elas podem ter, fazendo delas parceiras na educação do jovem, nunca se esquecendo de que estas alianças educativas devem ser formadas por pessoas que estejam diretamente em contato com o jovem e que sejam significativas para ele. Este modo de fazer implica em um desdobramento da ação educativa ou conjunto com os parceiros que vivem no meio imediato do jovem. 


\section{A formação em psico-educação}

Segundo a concepção psico-educativa de intervenção, a formação e a qualidade do educador são essenciais.

A formação em psico-educação é uma questão de saber, de saber-fazer e de saber-ser.

O SABER refere-se primeiramente ao conhecimento. Conhecimento das características gerais da clientela e das diferentes etapas de seu desenvolvimento. Conhecimento das habilidades sociais a serem desenvolvidas em cada uma das etapas, mas também competências parentais necessárias para o favorecimento deste desenvolvimento. Vários pais, particularmente entre os mais carentes (mães solteiras, não instruídas, pobres, etc) têm sido, eles próprios, violentos ou violentados, vítimas de negligência ou negligentes, etc. Daí a importância de ajudá-los a adquirir habilidades educativas indispensáveis ao desenvolvimento de seus filhos.

O saber supõe, igualmente, um bom conhecimento do meio da criança: organizações suscetíveis de ajuda (escola, lazer), mas também uma rede de adultos significativos para eles.

O SABER-FAZER refere-se às habilidades instrumentais do educador. É a caixa de ferramentas do educador na ação educativa. $\mathrm{O}$ educador necessita destas habilidades instrumentais em cada uma de suas operações profissionais:

\section{a) A observação}

Estamos falando de uma observação metódica das características da criança, das suas necessidades, de seu meio, da sua rede de relações. Falamos também de uma observação engajada e contínua que é feita na ação, no acompanhamento da criança, no vivido compartilhado com ela.

b) A avaliação diagnóstica

A partir de suas observações e do seu vivido compartilhado com a criança, e daquilo que ele compreende, o educador deve formular hipóteses quanto às necessidades do jovem e quanto ao tipo de apoio que ele precisará. Isto supõe que sejam colocadas em prática mecanismos de revisão destas hipóteses.

\section{c) O Planejamento}

A avaliação diagnóstica do jovem não tem outro objetivo senão o de estabelecer de maneira pragmática os objetivos e os meios de ajudá-lo a se desenvolver. A elaboração de um plano de trabalho para o jovem, estabelecido com ele, caso sua idade o permita, e associando os pais, representa muito mais 
do que uma técnica. O plano de trabalho ou o plano de cuidados constitui o contrato social entre o educador e seus parceiros que são o jovem e a família.

A participação do jovem e da família garante o realismo dos objetivos perseguidos. O perigo que espreita os educadores é de consagrar muito tempo e energia para observar, avaliar e planejar (muitas vezes com competência) sem retornar à ação e ao acompanhamento cotidiano. É um defeito observado com frequência em educadores, mesmo os mais instruídos ou os mais distanciados da ação (chefes, diretores, conselheiros, etc). Além disso, os educadores sociais mais implicados no acompanhamento do jovem no cotidiano podem estar tão envolvidos pelas suas urgências e as crises de todo tipo, que eles não têm mais tempo para refletir, parar para discutir suas orientações, e para formular um plano de intervenção.

Existe um equilíbrio essencial que deve ser assegurado entre o tempo consagrado para tomar conhecimento de uma situação, e a energia desprendida para implantar as condições necessárias para o desenvolvimento do jovem.

\section{d) A organização}

A organização consiste precisamente em implantar estas condições. Responder às necessidades do jovem, criar um meio de vida que favoreça sua transformação. Esta é a principal função do educador organizador.

\section{e) $\mathrm{A}$ animação}

A animação de um programa de acompanhamento (compartilhar da vida do jovem, propor atividades) é a pedra angular do trabalho do educador. Viver com, é, ao mesmo tempo, ser uma testemunha privilegiada do universo do jovem, compartilhar com ele sua realidade e ajudá-lo a dar um sentido pessoal a estes acontecimentos.

\section{f) A utilização}

A utilização concreta (espontânea e contínua) que fará o educador de todo o potencial educativo que contém o vivido compartilhado com a criança (ocasiões de relação, desenvolvimento de habilidades sociais), é a verdadeira chave da relação educativa.

Estas horas compartilhadas nestas situações de vida, permitem ao educador partir de acontecimentos para levar a criança a refletir sobre seu comportamento, sua maneira de entrar em relação, sobre suas atitudes em relação ao meio (amigos, familia, etc). A tomada de consciência do jovem permite-lhe fazer o aprendizado de comportamentos sociais que facilitam mais sua adaptação ao real do que sua marginalidade.

Após o saber e o saber-fazer, o educador deve se preocupar com 
o desenvolvimento do SABER-SER. A personalidade do educador é sua principal ferramenta de trabalho. Sua autenticidade, seu engajamento, sua coerência, sua ética, seu modo de ser justo, seu respeito, etc são os ingredientes essenciais para o estabelecimento de uma relação de confiança com o jovem. Relação que se tornará significativa e transformadora para o jovem.

Os jovens têm necessidade de modelos. Estes modelos podem ser imperfeitos, podem cometer erros, mas eles devem oferecer ao jovem o melhor deles mesmos. Se o amor e o engajamento não são suficientes, o amor e o engajamento são indispensáveis.

Os educadores são o bem mais precioso do sistema de ajuda à juventude. Uma seleção rigorosa e a exigência de uma formação mínima não exclui em nada a responsabilidade de oferecer a estas pessoas um apoio profissional regular e constante dada a importância do mandato que lhes é confiado, ou seja, o acompanhamento de jovem com grande dificuldade.

\section{A Supervisão}

A supervisão profissional constitui, para o educador, um lugar de reflexão sobre sua prática. Ela o ajuda a esclarecer seu modo de implicação no processo educativo. $O$ termo supervisão não é dos mais felizes, ele tem sempre uma conotação de hierarquia/subordinação. Na linguagem corrente o termo supervisão é, com frequência, sinônimo de controle ao passo que, para nós, ele significa acima de tudo um recuo, uma tomada de distância em relação a uma situação relacional e educativa. A supervisão pode ser individual ou feita em grupo.

O objetivo da supervisão individual é de chegar a uma melhor compreensão de si mesmo em relação ao trabalho que é feito. A criança fica no centro da supervisão. Essencialmente, a supervisão é um encontro de refle$x \tilde{a} o$ sobre o desenvolvimento da ação educativa: atitudes do educador, respostas da criança, vida do grupo, atividades, etc. Esta reflexão supõe que o educador conheça suas próprias ressonâncias emocionais, pois a reflexão torna-se difícil se ele estiver muito implicado no vivido compartilhado. A supervisão permite-lhe tomar certa distância, levando-o a ver melhor como ele se comporta no grupo. Se a supervisão leva o educador a tomar consciência de seus recursos e a utilizá-los melhor, ela pode também trazer-lhe o apoio de que necessita.

Por outro lado, a supervisão facilita ao educador tomar consciência de suas capacidades, de seus limites, dos sentimentos que ele mantém tanto em relação à criança, como em relação ao pessoal. De outra parte, a supervi- 
são permite-lhe aprender, examinar o trabalho realizado, considerar as consequências do programa, avaliar as interações no grupo. Graças às trocas que ela suscita, a supervisão também fornece ao educador uma ajuda para definir as diversas funções da equipe, para explorar ao máximo suas observações a fim de apreender as necessidades de cada criança, de adaptar seu quadro de vida a estas necessidades e avaliar os progressos.

O campo de intervenção do supervisor é a realidade profissional tal qual ela é vivida e trazida pelo educador.

A supervisão de grupo favorece as trocas de experiências entre colegas e apresenta algumas vantagens: reconhecimento de problemas semelhantes, compartilhar das soluções, ajuda mútua, definição de orientações, diminuição da ansiedade descobrindo que não estamos sozinhos com as nossas dificuldades.

A formação dos educadores em psico-educação e em ciências humanas em geral, não é um conjunto de receitas a serem fixadas. Ela deve ser integrada e ajustada permanentemente com a prática. A supervisão é uma ferramenta essencial para o educador que quer integrar saber, saberfazer e saber-ser.

\section{Conclusão}

Concluiremos este panorama da psico-educação citando três textos que ilustram os três aspectos da formação.

O saber

"Uma escola profissional tem a responsabilidade não somente de desenvolver o saber, mas de fazer dele um culto. Culto que não corre o risco de tornar-se paralisante, pois aquele que sabe possui o sentido da relatividade, e aquele que intervém descobre rápido a relatividade de sua ação" Gilles Gendreau ${ }^{6}$

\section{O saber-fazer}

"O que faz com que a psico-educação seja revolucionária é justamente que ela fêz uma ciência e uma arte do compartilhar da relação e da ação educativa no cotidiano, que muitas vezes, consideramos banal $e$ insignificante. Revolucionária também é lembrando a todos que o sujeito está no centro de toda intervenção que todos seus gestos, suas palavras, seus silêncios constituem uma linguagem e que escutar esta lingua-

6- Discurso de boas-vindas aos estudantes de psicoeducação, setembro (1982). (Gilles Gendreau era então o diretor de Escola de Psicoeducação da Universidade de Montreal - Canadá). 
gem é permitir-lhe a existência, é favorecer a crią̧ão de uma identidade, a emergência de uma autonomia. Permitir esta linguagem é compartilhar a vida cotidiana do sujeito e criar ao longo do dia das condições de atualização que tem nele".

\section{André Lebon?}

\section{O saber-ser}

“Algumas palavras foram tão desgastadas ou mal utilizadas que tiveram uma interpretação errônea: é o que acontece com os termos engajamento, disponibilidade, respeito pelo outro, amor, segurança. Sabemos, entretanto, que toda pessoa interrogada sobre o que ela viveu de positivo ou de negativo junto com um pessoal educativo durante sua infancia retorna estas expressões para dizer o que ela recebeu ou o que ela sentiu falta... Sem este enraizamento tecido pelos gestos quotidianos de uma convivência, todos os discursos teóricos sobre a afetividade parecem vãos. Ter descoberto na certeza de uma relação que seu ser é suficientemente reconhecido para acarretar uma mobilização de energias livremente concedidas em direção desta pessoa, tornar-se o motor essencial de todo desenvolvimento. Pouco importa que tenha tido gestos de irritação, de rejeições momentáneas, de injustiças passageiras, se este "devido" está ficando no mais profundo si mesmo".

\section{Abstract}

Michel Lemay ${ }^{8}$

This paper presents the general lines of socio-educacional intervention model developed and implemented in Canada, called Psychoeducation. A brief history is made telling about the first days of a specialized education to children and adolescents in psycho-social risk situation. At the end there is the characterization of Psycho-education as the better educational practice done in institutions, the theoretical concepts underlying this approach and the principles tied to professional training.

Key words: Psycho-education - socio-educational interventionprofessional training.

Palavras chaves: Psico-educação - Intervenção Sócio-educativa - Formação Profissional

7- Conferência feita na Escola de educadores especializados de Genebra -Suiça, outubro

8- Capul, Maurice; Lemay, Michel (1996). A educação especializada, Érès. 
